\title{
Transpedicular Screw Fixation for Microinstability in Recurrent Lumbar Disc
}

Mohammed El-Gebaly Ahmed Alhady ${ }^{1, *}$ MD., Mohamed Hassan Mansour ${ }^{2}$ MD. and Mostafa Obraby ${ }^{2}$ MD.

* Corresponding Author:

Mohammed El-Gebaly Ahmed

Alhady

M.gebali@domazhermedicine.edu.eg

Received for publication June 17, 2020; Accepted November 11, 2020; Published online November 11, 2020.

Copyright 2020 The Authors published by Al-Azhar University, Faculty of Medicine, Cairo, Egypt. All rights reserved. This an open-access article distributed under the legal terms, where it is permissible to download and share the work provided it is properly cited. The work cannot be changed in any way or used commercially.

doi: $10.21608 /$ aimj.2020.28901.1213

${ }^{1}$ Department of Neurosurgery, Damietta Faculty of Medicine, AlAzhar University, Egypt

${ }^{2}$ Department of Neurosurgery, Cairo Faculty of Medicine, AlAzhar University, Egypt

\begin{abstract}
Background: Microinstability represents the first phase of the degenerative cascade and has specific pathoanatomical and clinical characteristics (low back pain) in the interested vertebral segment, without the presence of spondylolisthesis it is more prominent in recurrent lumbar disc.

Objective: The objective of this study is to evaluate the surgical outcome of trans-pedicular screw fixation for microinstability in recurrent lumbar disc herniation with ipsilateral or bilateral transpedicular screw fixation, with highlights on lumbosacral instability classification.

Patient and methods: Two hundred patients with recurrent lumbar disc herniation were managed surgically by discectomy, curettage and unilateral transpedicular screw fixation at the offending side (100 patients among 200 patients of recurrent lumbar disc), or discectomy with endplate curettage and bilateral transpedicular screw fixation (100 patients among 200 patients of recurrent lumbar disc).

Results: No significant difference was reported between both groups regarding patient age, gender, level of the disc. Surgery was on left side in 120 patients. The clinical outcome at the last follow up visit revealed that, recurrence and dural tears were confined to group A (unilateral) (each was reported in 1 patient), while root injury and spinal instability were confined to group B (Bilateral) (one patient for each. The recovery rate was 0.888 for group $\mathrm{A}$ and 0.807 for group $\mathrm{B}$, with statistically significant difference.

Conclusion: unilateral transpedicular screw fixation for recurrent lumbar disc provides slightly better outcome than bilateral approach, especially for recovery rate.

Keywords: Microinstability; Recurrent lumbar disc; Unilateral lumbosacral fixation; $\quad$ Lumbosacral instability; Spondiololythesis.
\end{abstract}

Disclosure: The authors have no financial interest to declare in relation to the content of this article. The Article Processing Charge was paid for by the authors.

Authorship: All authors have a substantial contribution to the article.

\section{INTRODUCTION}

Microinstability represents the initial stage of the degenerative cascade defined by Kirkaldy-Willis. From the clinical and pathoanatomical point of views, it had a specific criteria (e.g., low back pain) corresponding to interested segment of vertebrae, and absent spondylolysthesis on the radiography carried in flexion-extension. It considered grade-1instability and equals to grade zero spondiololythesis. ${ }^{1}$

It is more apparent in recurrent lumbar disc herniation, ipsi- or contra-lateral, in a patient who is pain free at least for 6 months after primary discectomy. $^{2}$

Recurrent lumbar disc herniation (RLDH) is a major etiology of surgical failure, with an incidence of 5 to $23 \%$, that increased with extended follow up period. $^{3,4,5}$

The surgical choices for recurrent herniation are usually limited. This limitation ascribed to many factors, for example the duration of operative time (it usually needs a longer time). The second factor of limitation of surgical options is the high rate of comorbidities. $^{6,7,8}$

The current study aimed to assess (evaluate) the surgical outcome of Transpedicle screw fixation for microinstability in recurrent herniation of lumbar disc with ipsilateral or bilateral transpedicle fixation by screws, with highlights on the classification of lumbosacral instability.

\section{PATIENTS AND METHODS}

The current work was designed as a prospective, randomized, comparative research work. It included patients who presented with herniation of the lumbar disc for the first time. It conducted from January 2014 to January 2018 at Al-Azhar university hospitals. It included 200 subjects with recurrent herniation of the lumbar disc. They were defined into: Group A (100) patients, managed by discectomy, curettage induced fusion with single side [unilateral] Transpedicle screw fixation, and Group B 
(100) patients, managed by discectomy with endplate curettage induced fusion and bilateral Transpedicle screw fixation.

The preoperative criteria were: dynamic pain of the lower back, which associated or not associated with radicular pain developed after primary lumbar discectomy for a duration equal of longer than 6 months; existence of radicular, unilateral recurrent pain with no response to medical therapy for a duration of 6 weeks or longer; and MRI revealed herniated disc at the identical level of the first discectomy, dynamic x-ray of lumbosacral spine showing no sliding.

Patients experienced one or more of the following were excluded: stenosis of spinal canal at multiple segments, disc herniation at adjacent levels; lumbosacral sliding in dynamic $\mathrm{x}$-ray or with nay deformities of the spine. The preoperative manifestations were dynamic pain of the lower back, single side radicular or claudication pain of the lower limb.

Radiological evaluation was achieved by lumbosacral X-ray (lateral, A-P, oblique and dynamic views in different positions (neutral, flexion, and extension) and magnetic resonance with gadolinium augmentation.

Surgical technique: All patients were operated under general anesthesia. The surgery was done through previous mark of the scar. Laminectomy and disc resection were performed done with extreme caution [at scare removal from lamina] to create a perfect recognition of laminectomy edges of the previous surgery. Then, curettes were inserted to completely dissect the scar from bone margins and to meticulously define the bone attached to the scar to prevent violation of the dura. Facet recognition followed by pedicles permits the scar tissue to be completely separated from bone and also permits an accurate recognition of the lumbar disc space. Exposure had been advanced laterally, to permit good visualization and prevent damage of the nerve root (especially lateral edge of the nerve). The disc fragment was then exposed by gentle mobilizations with nerve root medially retracted. Occasionally, nerve root was adherent to herniated fragment of the disc or other ligamentous parts and sharp dissection to separate adherent parts was implemented. In first group [A], total facetectomy had been completed prior to nerve root dissection, until clear visualization of the pedicle. This led to recognition of disc structure and the nerve root, to achieve a decompression completely without the need to extensively dissect and retract neural tissues then unilateral fixation by transpedicle screw was done. In the second group $[\mathrm{B}]$, the same was done with bilateral fixation by transpedicle screw. For all patients, curettage of the end plates of the herniated disc was performed. A lateral view image obtained by fluoroscopic projection had been obtained during the whole surgery for confirmation of accurate placing of the screw in the desired level. All subjects had been instructed to start ambulation 6 hours after surgery. Japanese Orthopedic Association scoring system (JOA; maximum score, 29 points) ${ }^{9}$ had been used to assess the neurological state and clinical results. All subjects were examined in the pre- and post-operative times to assess their neurological status and clinical improvement.

The rate of complete recovery had been calculated by the following equation: "recovery rate = [postoperative- preoperative JOA score] /[normalpreoperative JOA score].

Ethical considerations: the research plan (protocol) was revised and accepted by the local board for research ethics (Al-Azhar faculty of Medicine), and all patients signed an informed consent for participations. They were assured that, the collected data were for research purposes, and their confidentiality was guaranteed

Data analysis: The collected data were coded and fed to a statistical software package (The SPSS package), version 18 (SPSS Inc., USA). 1Qualitative variables were expressed in their number and percentage, while quantitative data presented in their mean and standard deviations (SD). Groups were compared by independent samples $(\mathrm{t})$ test and Chi square for quantitative and qualitative data respectively. $\mathrm{P}$ value $2<0.05$ was set as the margin of significance.

\section{RESULTS}

Patients of group A were 62 males and 48 females; the mean age was 45 years (ranged between 35 and 60 years). The level was L5-S1 (30), L4-5 (60), L3-4 (6), L2-3 (2) and L2-1 (2). In group B, there were 60 males and 40 females; the mean age was 40 years (ranged between 30 and 65 years). The affected levels were L5-S1 (40), L4-5 (55), L3-4 (3), L2-3 (1) and L2-1 (1) (Table 1).

The side was the left in $120(60 \%)$ and the right side in $80(40 \%)$ of studied subjects. The mean follow up period was $36 \pm 785$ [range $24-48$ months]. The mean recurrent time after the primary discectomy was $18 \pm 6.01$ months [range 10-30 months].

The clinical outcome at the last follow up visit revealed that, recurrence and dural tears were confined to group A (each was reported in 1 patient), while root injury and spinal instability were confined to group B (one patient for each (Table 2).

Regarding recovery rate, it was 0.888 for group A and 0.807 for group B, with statistically significant difference (Table 3 ). 


\begin{tabular}{|c|c|c|c|}
\hline & GA & GB & $\begin{array}{c}\mathrm{P} \\
\text { value }\end{array}$ \\
\hline $\begin{array}{l}\text { Average age } \\
\text { (years) }\end{array}$ & 45 & 40 & $>0.05$ \\
\hline $\begin{array}{l}\text { Sex } \\
\text { /female) }\end{array}$ & $52 / 48$ & $60 / 40$ & $>0.05$ \\
\hline Level of L 5-S1 & 30 & 40 & \multirow{5}{*}{$>0.05$} \\
\hline Level of L 4-5 & 60 & 55 & \\
\hline Level of L3-4 & 6 & 3 & \\
\hline Level of L2-3 & 2 & 1 & \\
\hline Level of L 1-2 & 2 & 1 & \\
\hline $\begin{array}{l}\text { Total duration of } \\
\text { follow-up } \\
\text { (months) }\end{array}$ & $\begin{array}{c}36.0(24.0- \\
48.0)\end{array}$ & $\begin{array}{c}36.0 \\
(24.0- \\
48.0)\end{array}$ & $>0.05$ \\
\hline $\begin{array}{l}\text { total } \\
\text { score }\end{array}$ & 15.5 & 16.0 & $>0.05$ \\
\hline
\end{tabular}

GA: group A; GB: group B; PO: preoperative; JOA: Japanese Orthopedic Association

Table 1: Presenting the preoperative data.

\begin{tabular}{|l|c|c|c|}
\hline \multicolumn{1}{|c|}{ Clinical outcome } & $\begin{array}{c}\text { Group } \\
\mathrm{A}\end{array}$ & $\begin{array}{c}\text { Group } \\
\mathrm{B}\end{array}$ & $\begin{array}{c}\text { P } \\
\text { value }\end{array}$ \\
\cline { 1 - 3 } $\begin{array}{l}\text { Recurrence (second } \\
\text { recurrence) }\end{array}$ & 1 & 0.05 \\
\hline Dural tear & 1 & 0 & \\
\hline Root injury & 0 & 1 & \\
\cline { 1 - 3 } Instability of the spine & 0 & 1 & \\
\hline
\end{tabular}

Table 2: The clinical outcome among studied groups

\begin{tabular}{|l|c|c|c|}
\hline \multicolumn{1}{|c|}{$\begin{array}{c}\text { The rate of } \\
\text { recovery }\end{array}$} & Group A & Group B & $\begin{array}{c}\text { P } \\
\text { value }\end{array}$ \\
\hline $\begin{array}{l}\text { Postoperative } \\
\text { - preoperative } \\
\text { score)/ } \\
\begin{array}{l}\text { (normal- } \\
\text { preoperative } \\
\text { score) }\end{array}\end{array}$ & $\begin{array}{c}(27.5- \\
(29.5) /\end{array}$ & $\begin{array}{c}(26.5-16) / \\
(29.0-16.0) \\
=\end{array}$ & $<0.058)$ \\
\hline
\end{tabular}

Table 3: The rate of recovery (percentage) among studied groups.

\section{DISCUSSION}

The word 'instability' is still poorly defined in-spite of being an important etiology of pain affecting the lower back and can be associated with substantial disability. There are two main categories: the first is macroinstability and the second is microinstability. ${ }^{10}$

Macroinstability (radiological instability) is apparent in dynamic $x$-rays and staged on the basis of the sliding degree into 4 degrees and a fifth grade was added by $\mathrm{Hu}$ et al. $^{11}$ at 2008 , and there are medicolegal implications due to its radiological presence. The second is microinstability which is manifested clinically but without apparent radiological sliding, and called first degree instability or zero-degree spondiololythesis. So, the grouping of spondylolysthesis may be modified. ${ }^{1}$ The next table showed proposed classification

Table (4): showing modification of grading of spondiololythesis ${ }^{1}$

\begin{tabular}{|l|l|l|}
\hline Instability & Spondiololythesis & \multicolumn{1}{|c|}{ Comment } \\
\hline 1 & Zero grade & $\begin{array}{l}\text { The grade of mechanical instability = the initial stage of degenerative } \\
\text { process: microinstability= dynamic pain of the lower back without } \\
\text { radiological evidence of sliding }\end{array}$ \\
\hline 2 & First grade & Up to 25\% translation of cranial vertebra \\
\hline 3 & Second grade & Up to fifty \% translation of cranial vertebra \\
\hline 4 & Third grade & Up to seventy-five \% translation of the cranial vertebra \\
\hline 5 & Fourth grade & $\begin{array}{l}\text { Up to one hundred percentage [100.00\%] translation of the cranial } \\
\text { vertebra }\end{array}$ \\
\hline 6 & Fifth grade & Complete vertebral Ptosis \\
\hline
\end{tabular}

The beginning of the microinstability concept has increased the diagnostic capabilities towards pain of the lower part of vertebral column [i.e, back pain] and the treatment options. However, medicolegal (ML) issues related to diagnostic and therapeutic interventions had been increased. But, there was no absolute measurement to diagnose micro-instability in spite of the test proposed by Landi et al. ${ }^{12}$

So, authors restricted the current study to cases with advanced degenerative changes and the recurrent herniation of the lumbar disc, considered the good illustration of lumbosacral microinstability. The precise examination of the radiological images permits, on time, diagnosis of microinstability with a

good value of prediction. However, it is not the absolute value of prediction. Many practical and ML conditions add a difficulty on the surgeon to deal with pathology without guidelines. ${ }^{12}$

The optimal and gold-standard surgical intervention for recurrent herniation of the lumber disc remains controversial. ${ }^{13}$ Two fundamental points may be responsible for controversy: The first is the existence of unclear planes between anatomical structures and the perineuralscarring ${ }^{14}$ while the second is the successive degenerative changes either at the level of pervious discectomy, or at the adjacent part of rigidly fused vertebral segemtns. ${ }^{1}$ A second point related to the recurrent lumbar surgical intervention is the postoperative successive degenerative alterations after the primary operation, like gradual progressive 
loss of the disc space and superior facet impingement causing subsequent foraminal stenosis. A specific attention thus paid to the degenerative cascade at the facet itself which directed the surgeon to perform medial facetectomy to release pain related to nerve root and/or facet pain. Padua et al. agreed that: the removal of a big segment of the joint in the first intervention, may cause joint destabilization during secondary discectomy and associated with postoperative mechanical instability. ${ }^{15}$

In the current research, discectomy and curettage induced fusion was performed in the both groups, with single transpedicle fixation at the diseased side [exclusively performed in the first group], and bilateral fixation in the second group [group B].

Regarding the complication, the nerve root insult was more presented in the B-group than first group. This explained by extensive facetectomy performed in the first group [group A], so safe nerve root exploration was simple and stress-free, while in the second group, partial facetectomy had been performed with consequent inevitable great vulnerability of the nerve root to insult.

Regarding instability of the spine, one patient was established on clinical and radiological bases in the second group. The documented instability could be explained by the nonexistence of support by screws during postoperative time, and no good time had been determined for bone fusion of the curetted disc to occur.

Recurrence was only reported by one patient in the first group, while no recurrence was recorded in the second one. These data are comparable to Shazly et al. $^{16}$

Different trials suggested that, fusion through discspace decreases, if not, completely eradicates recurrent herniation risk of the disc at the operated level. ${ }^{17}$

The outcome in unilateral [first group] was better than the second one as the recovery rate was better. All represented previous data support the perception of facetectomy, discectomy, curettage and unilateral fixation in secondary disc surgical intervention. The prior opinion is reinforced also by Nguyen et al. ${ }^{18}$, who characterized the initial stage of degenerative process as the stage of dysfunctional instability. This stage is also described as the stage of active discopathy. Also, elucidation of the pathological changes in the first stage disturbing the components and mechanisms of the motor spinal unit which was described by Kirkaldy-Willis and Farfan ${ }^{19}$, may be identified by radiological investigations or not, so that the presence of the lower back dynamic pain in recurrent lumbar surgery was a marker for fusion (alone or with instrumentation) as it characterize the mechanical type of instability.

Taking previous data into account, curettage of nucleus pulposus and the affected joint was performed for all patients in the two groups. The idea of curettage was advocated by numerous surgeons, Dandy was the most famous one of those surgeons and states that no absolute need for spinal fusions and the nucleus pulposus must be curetted out with the affected joint. ${ }^{20}$

The principle and sole aim of curettage is to enhance fusion of the vertebral body. Others like Cloward firstly designated vertebral fusion without posterior screw fixation in $1953 .{ }^{20}$ His technique was adopted by other surgeons. However, it failed to gain a wide acceptance.

As the spinal fusion is the definitive and crucial aim of the spinal instrumentation, curettage was carried out for all patients while screw fixation (instrumentation) was carried out only in one group. The associated increase of stiffness of fused vertebrae will lead to decrease of the mineral content of bone of adjacent vertebrae, and anticipated increase of pathology in such vertebrae due to high stress at levels adjacent to the fusion. ${ }^{21}$

Optimal biomechanical settings for fused segments could be accomplished by the usage of fixations systems with less rigidity. An additional advantage of less rigid systems used in fixation include the reduction of adverse effects due to instrumentations in the adjacent levels. ${ }^{22}$

Consequently, unilateral fixation of pedicle screws was recognized as a technique to reduce the stiffness of the instrumented vertebrae segeemnts. Chen et $\mathrm{al}^{23}$ concluded that unilateral (single side) fixation was suitable and good intervention to retain the stability of the spine.

One weak point of the current work is that, the study doesn't cover other subgroups of microinstability.

\section{CONCLUSION}

One-sided transpedicle fixation by screws for recurrent herniation of the lumbar disc provides slightly better outcome than bilateral approach, especially for recovery rate. Otherwise, both techniques were comparable as regard to recorded postoperative complications.

\section{REFERENCES}

1. Mansour MH, Behairy HM, Abo Shosha MM, et al. Management of recurrent lumbar disc herniation with or without ipsilateral transpedicular screw fixation. Life Sci $J$ 2016;13(12):106-11.

2. Swartz KR and Trost GR. Recurrent lumbar disc herniation. Neurosurg Focus. 2003; 15(3): E10.

3. Aizawa $\mathrm{T}$, Ozawa $\mathrm{H}$, Kusakabe $\mathrm{T}$, et al. Reoperation for recurrent lumbar disc herniation: a study over a 20-year period in a Japanese population. J Orthop Sci 2012; 17:107-13.

4. Lebow RL, Adogwa O, Parker SL, et al. Asymptomatic same-site recurrent disc herniation after lumbar discectomy: results of a prospective longitudinal study with 2-year serial imaging. Spine (Phila Pa 1976) 2011; 36:214751. 
5. Dave BR, Degulmadi D, Krishnan A, et al. Risk Factors and Surgical Treatment for Recurrent Lumbar Disc Prolapse: A Review of the Literature. Asian Spine J. 2020 Feb;14(1):113-21.

6. El-Kader HE. Transforaminal lumbar interbody fusion for management of recurrent lumbar disc herniation. Asian Spine J 2016; 10:52-8.

7. Mamuti M, Fan S, Liu J, et al. Mini-open anterior lumbar interbody fusion for recurrent lumbar disc herniation following posterior instrumentation. Spine (Phila Pa 1976) 2016;41: E1104-14.

8. Albayrak S, Ozturk S, Durdag E, et al. Surgical management of recurrent disc herniations with microdiscectomy and long-term results on life quality: detailed analysis of 70 cases. J Neurosci Rural Pract 2016; 7:87-90.

9. Chiba K, Toyama Y, Matsumoto M, et al. Intraspinal cyst communicating with the intervertebral disc in the lumbar spine: discal cyst. Spine $2001 ; 26: 2112-8$.

10. Barza T, Melloh M, Lord SJ, et al. A conceptual model of compensation/decompensation in lumbar segmental instability. Medical Hypotheses 2014; 83 (3): 312-6.

11. $\mathrm{Hu}$ SS, Tribus CB, Diab $M$, et al Spondylolisthesis and spondylolysis. $J$ of Bone Joint Surg Am. 2008; 90:656-71.

12. Landi A, Gregori F, Mancarella C, et al. Detection of Spinal micro-instability: A Real Clinical and Forensic Problem. J Spine 2015; 4: e119.

13. Fu TS, Lai PL, Tsai TT, et al. Long-term results of disc excision for recurrent lumbar disc herniation with or without posterolateral fusion. Spine (Phila Pa 1976) 2005; 30:2830-4.

14. Ebeling U, Kalbarcyk H and Reulen HJ. Microsurgical reoperation following lumbar discsurgery. Timing, surgical findings, and outcomein 92 patients. J Neurosurg. 1989; 70:397-404.
15. Padua R, Padua S, Romanini E, et al. Ten- to 15year outcome ofsurgery for lumbar disc herniation: Radiographic instability and clinical findings. Eur Spine J. 1999; 8:70-4.

16. El Shazly AA, El Wardany MA and Morsi1 AM. Recurrent lumbar disc herniation: A prospective comparative study of three surgical management procedures. Asian J Neurosurg. 2013; 8(3):13946.

17. Vishteh AG and Dickman CA. Anterior lumbar microdiscectomy and interbody fusion for the treatment of recurrent disc herniation. Neurosurgery 2001; 48:334-7.

18. Nguyen C, Poiraudeau S and Rannou F. From Modic 1 vertebral- endplate subchondral bone signal changes detected by MRI to the concept of 'active discopathy'. Ann Rheum Dis. 2015; 74:1488-1494.

19. Kirkaldy-Willis WH and Farfan HF. Instability of the lumbar spine. Clin Orthop Relat Res. 1982:110.

20. Cloward RB: The treatment of ruptured lumbar intervertebral discs by vertebral bodyfusion. I. Indications, operative technique, aftercare. $J$ Neurosurg 1953; 10(2):154-68.

21. Shono Y, Kaneda K, Abumi K, et al. Stability of posterior spinal instrumentation and its effects on adjacent motion segments in the lumbosacral spine (1) Spine (Phila Pa 1976); 1998; 23: 15508.

22. Korovessis P, Papazisis Z, Koureas G, et al. Rigid, semirigid versus dynamic instrumentation for degenerative lumbar spinal stenosis: a correlative radiological and clinical analysis of short-term results. Spine (Phila Pa1976) 2004; 29: $735-42$.

23. Chen HH, Cheung Hh, Wang WK, et al. Biomechanical analysis of unilateral fixation with interbody cages. Spine 2005; 30: E92-6. 